\title{
Beneficial Effects of the NMDA Antagonist Ketamine on Decision Processes in Visual Search
}

\author{
Kelly Shen, ${ }^{1}$ Sarah Kalwarowsky, ${ }^{1}$ Wendy Clarence, ${ }^{2}$ Emiliano Brunamonti, ${ }^{1,2}$ and Martin Paré ${ }^{1,2,3}$ \\ ${ }^{1}$ Centre for Neuroscience Studies and Departments of ${ }^{2}$ Physiology and ${ }^{3}$ Psychology, Queen's University, Kingston, Ontario, Canada K7L 3N6
}

The ability of sensory-motor circuits to integrate sensory evidence over time is thought to underlie the process of decision-making in perceptual discrimination. Recent work has suggested that the NMDA receptor contributes to mediating neural activity integration. To test this hypothesis, we trained three female rhesus monkeys (Macaca mulatta) to perform a visual search task, in which they had to make a saccadic eye movement to the location of a target stimulus presented among distracter stimuli of lower luminance. We manipulated NMDA-receptor function by administering an intramuscular injection of the noncompetitive NMDA antagonist ketamine and assessed visual search performance before and after manipulation. Ketamine was found to lengthen response latency in a dose-dependent fashion. Surprisingly, it was also observed that response accuracy was significantly improved when lower doses were administered. These findings suggest that NMDA receptors play a crucial role in the process of decision-making in perceptual discrimination. They also further support the idea that multiple neural representations compete with one another through mutual inhibition, which may explain the speedaccuracy trade-off rule that shapes discrimination behavior: lengthening integration time helps resolve small differences between choice alternatives, thereby improving accuracy.

\section{Introduction}

The cognitive control of action entails a decision process by which our brain is thought to temporally integrate the evidence that supports available choice alternatives before making a choice. This integration process is theoretically validated because neural representations of the sensory evidence are inherently variable and thus unreliable at any given instant (for review, see Bogacz, 2007). Several mathematical models have postulated that decisions are based on noisy evidence about the different sensory signals, which is integrated over time until the representation of one alternative reaches a criterion level (for review, see Smith and Ratcliff, 2004).

Psychophysical observations that visual discrimination improves with increasing stimulus duration support the view that sensory evidence is accumulated over time (Bergen and Julesz, 1983; Saarinen, 1988; Shibuya and Bundesen, 1988; Britten et al., 1992; Verghese and Nakayama, 1994; Ratcliff and Rouder, 2000; Bodelón et al., 2007) (but see Kiani et al., 2008). Neurophysiological studies of sensory-motor neurons in decision tasks corroborate this interpretation. In visual search tasks, the activity of sensory-motor neurons in the frontal eye field (FEF) (Thompson et al., 1996; Bichot and Schall, 1999), lateral intraparietal area

Received Dec. 21, 2009; revised May 28, 2010; accepted June 21, 2010.

This research was supported by grants from the Canadian Institutes of Health Research (CIHR MOP 38089) and Queen's University (to M.P.). K.S. holds a postgraduate scholarship from the Natural Sciences and Engineering Council of Canada. K.S. and M.P. contributed to the implementation of the experiments and wrote the manuscript: K.S., S.K., and W.C. contributed to the training of the animals and the collection of the behavioral data; K.S., S.K., and E.B. contributed to the data analysis; M.P. conceived of and supervised all aspects of the study.

Correspondence should be addressed to Martin Paré, Department of Physiology, Queen's University, Kingston, ON, Canada K7L 3N6. E-mail: pare@biomed.queensu.ca.

DOI:10.1523/JNEUROSCI.6317-09.2010

Copyright $\odot 2010$ the authors $\quad 0270-6474 / 10 / 309947-07 \$ 15.00 / 0$
(LIP) (Thomas and Paré, 2007; Ogawa and Komatsu, 2009), and superior colliculus (SC) (McPeek and Keller, 2002; Shen and Paré, 2007) evolves over time to gradually signal the location of the target selected for an eye movement. Similar observations about the build-up of decision-related activity in these brain regions have been reported using the random-dot motion discrimination task (Horwitz and Newsome, 1999; Kim and Shadlen, 1999; Shadlen and Newsome, 2001; Roitman and Shadlen, 2002). In keeping with the rise-to-threshold decision-making models, neural activity in both tasks reflects the quality of the incoming sensory information as well as the associated decision.

The recurrent excitatory connections between decision units combined with the slow kinetics of the NMDA synaptic current have been proposed as a candidate cellular mechanism underlying the slow accumulation of sensory evidence (Wang, 2002). Data supporting the former is extensive (for review, see Douglas and Martin, 2007), but there is a lack of direct experimental evidence to support the latter and other cellular mechanisms could be at play (for review, see Durstewitz and Seamans, 2006) (Mongillo et al., 2008). To elucidate the importance of the NMDA receptor in decision processes, we impaired its integrity by administering ketamine, a noncompetitive antagonist of the NMDA receptor, while monkeys performed a visual search task. If NMDA receptors are involved in the process of neural activity integration underlying the accumulation of sensory evidence, it is predicted that their blockade would cause the integration process to slow down and become noisier, thereby causing an increase in response latency and potentially a decrease in response accuracy. Alternatively, inhibitory interactions between decision units, as posited by certain models (Usher and McClelland, 2001), would predict an increase in both response latency and accuracy if longer integration time enhanced differences in signals between units. 
A preliminary report of the following data was previously presented (Kalwarowsky et al., 2008).

\section{Materials and Methods}

Data were collected from three female rhesus monkeys (Macaca mulatta; called G, H, and F; $5.0-7.0 \mathrm{~kg} ; 9-10$ years old). All animal care and experimental protocols were approved by the Queen's University Animal Care Committee and were in accordance with the Canadian Council on Animal Care guidelines. The surgical procedure, stimulus presentation, and data acquisition have been previously described in detail (Shen and Paré, 2006). Monkeys were housed in large enclosures (Clarence et al., 2006) and received both antibiotics and analgesic medications during the postsurgery recovery period, after which they were trained with operant conditioning and positive reinforcement to perform fixation and saccade tasks for a liquid reward until satiation.

Experimental procedures. Before experiments were conducted and data collected, animals were trained (at least 15 training sessions) to perform well above chance level in the visual search task described below. Each experimental session was composed of a control block of trials, during which baseline performance was assessed, followed by a treatment block, each consisting of 500-800 trials. Between the control block and the treatment block, animals randomly received an intramuscular injection of ketamine (Ketaset; $0.25,0.5,0.75$, or $1 \mathrm{mg} / \mathrm{kg}$ diluted to $0.3 \mathrm{ml}$ with saline), $0.3 \mathrm{ml}$ of saline solution $(0.9 \%$ sodium chloride) as a vehicle control, or no injection (to control for waning motivation as the animals became more satiated). Although ketamine is a dissociative anesthetic, doses $\leq 1.0 \mathrm{mg} / \mathrm{kg}$ have been reported not to cause debilitating effects on behavior while reliably affecting saccade latency and metrics (Shiigi and Casey, 1999; Condy et al., 2005; Stoet and Snyder, 2006; Brunamonti et al., 2007). Data were collected from three sessions per treatment per monkey, with the exception of one additional session collected from monkey $\mathrm{G}$ with a ketamine dose of $1.0 \mathrm{mg} / \mathrm{kg}$. Before this study, each monkey had received a varying total amount of ketamine for anesthetic purposes: monkey G, $17.5 \mathrm{ml}$; monkey H, $8.3 \mathrm{ml}$; and monkey F, $8.1 \mathrm{ml}$.

Behavioral paradigm. Each visual search trial (Fig. $1 \mathrm{~A}$ ) began with the appearance of a fixation spot $\left(0.5^{\circ}\right)$ in the center of the screen and animals were required to foveate it within $1000 \mathrm{~ms}$ of its appearance. The visual search display was then presented with the simultaneous disappearance of the fixation spot. The search display consisted of eight stimuli arranged concentrically at $10^{\circ}$ of eccentricity with a diameter of $1^{\circ}$. Seven distracters had fixed luminance $\left(10.6 \mathrm{~cd} / \mathrm{m}^{2}\right)$ and one target had a luminance that varied randomly between $10.9,11.2,11.9,13.4,16.7,20.4$, $24.5,45.2$, and $76.6 \mathrm{~cd} / \mathrm{m}^{2}$. These stimulus luminance differences translated into percentage contrast differences of $2.7,5.3,10.9,20.9,36.5,48.0$, $56.7,76.5$, and $86.1 \%$. The location of the target also varied randomly between trials. Some data were collected in sessions in which the target luminance levels 11.2 and $45.2 \mathrm{~cd} / \mathrm{m}^{2}$ were not presented to the animals. Monkeys were given $500 \mathrm{~ms}$ to initiate a saccade within a computerdefined window $\left(2^{\circ} \times 2^{\circ}\right)$ around the target stimulus and were required to maintain fixation for $200-300 \mathrm{~ms}$. If monkeys fixated on the target after a single saccade, the trial was labeled as correct and the animal given the maximal liquid reward. If the animal made more than one saccade before fixating the target, the trial was labeled as incorrect and a smaller reward was given. If the target was not found within $2000 \mathrm{~ms}$ of visual array onset, no reward was given and the ensuing intertrial interval was lengthened (2000-2500 vs 500-1000 ms).

Data analysis. To assess visual search performance, response accuracy (the probability that the first saccade landed on target) and response latency (the time between the onset of the search display and the initiation of the first saccade) were calculated for each stimulus luminance difference before and after each treatment.
The effect of ketamine on response latency was quantified by calculating the percentage change in response latency. To do so, we took the latency of the response in each trial of the treatment block, subtracted the mean latency observed in the control block at the corresponding stimulus luminance difference, and divided this difference by that same mean control-block latency. Student's $t$ tests were used to determine whether the response-latency distribution in the treatment block was significantly different from zero $(p<0.05)$.

For each animal and treatment, the psychometric function describing how response accuracy varied with the stimulus luminance difference was quantified with a best-fit Weibull function (Weibull, 1951): $W(l)=$ $\gamma-(\gamma-\delta) \cdot \exp \left(-(t / \alpha)^{\beta}\right)$, where $l$ is stimulus luminance difference, $\alpha$ is the time at which the function reaches $64 \%$ of its full growth, $\beta$ is the slope, $\gamma$ is the upper limit of the function (constrained to 1.0, i.e., perfect discrimination), and $\delta$ is the lower limit of the function (constrained to 0.125 , i.e., chance discrimination). From this function, the discrimination threshold (i.e., the stimulus luminance difference at which the Weibull function reached $64 \%$ of its maximum) was taken as a measure of response accuracy. All Weibull functions had $R^{2}>0.88$ (mean, 0.99; range, $0.88-1.0$ ).

Changes in accuracy following ketamine injections were quantified by calculating the percentage change in threshold discrimination: the difference between the thresholds computed in the treatment block and the associated control block divided by that same control-block threshold. The statistical significance of the differences in accuracy between control and treatment blocks was determined using repeated $\chi^{2}$ tests (significance level corrected to $p<0.0166$ ) on the three intermediate levels of stimulus luminance difference, which fell between the inflection points of the Weibull functions (i.e., within its second and third quartile) and which corresponded to percentage contrast differences of 20.9, 36.5, and $48.0 \%$.

\section{Results}

We collected and analyzed a total of 49,650 trials for this study. Figure $1 B$ shows representative eye position traces following the onset of the visual search display before and after a $0.5 \mathrm{mg} / \mathrm{kg}$ ketamine injection in monkey G. Ketamine both increased saccade latency and decreased saccade amplitude. We also observed significant postsaccadic drift in eye position, indicative of the oculomotor neural integrator rendered leaky. To capture the time course of each dose of ketamine, we computed saccade amplitude for $1 \mathrm{~min}$ intervals following ketamine injection, along with the mean saccade amplitude for the entire control block. Figure $2 \mathrm{~A}$ illustrates such data from the session depicted in Figure $1 B$ for monkey $\mathrm{G}$. In this animal, saccade amplitude was consecutively significantly shorter from 2 to 19 min after the injection $(p<0.05$, rank-sum test). The concomitant increase in response latency showed a similar time course (Fig. $2 \mathrm{~B}$ ), reaching a peak of $52.6 \%$ increase from the control block ( $232 \mathrm{vs} 152 \mathrm{~ms}$ ) within 10 
A

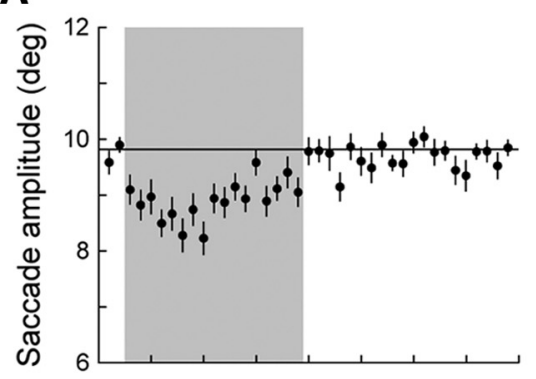

B

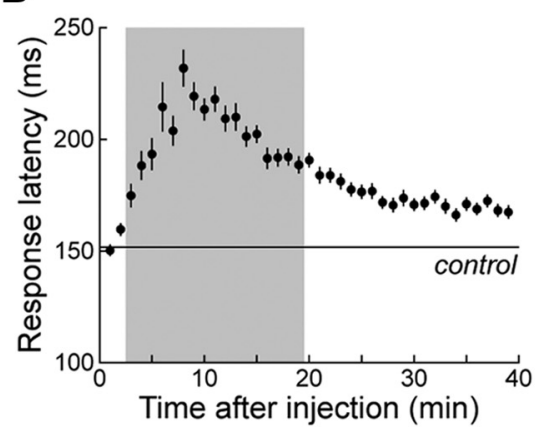

C

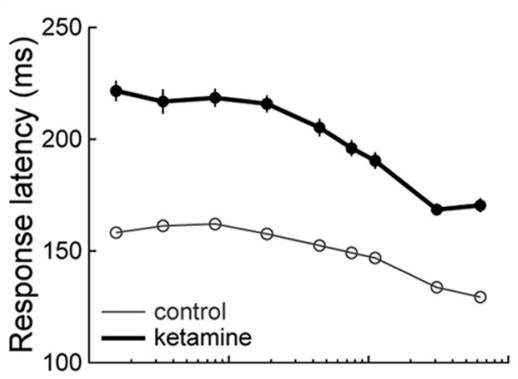

D

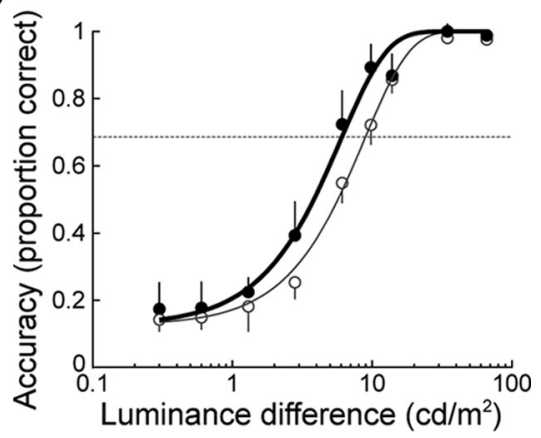

the lower limit of normal latency distributions (Paré and Munoz, 1996). The predicted response latencies from this simple model are therefore overestimations, and any increase in response latency found with this stringent test is solid evidence for slowing in perceptual processing. We found a significant increase in response latency at each ketamine dose and in each animal, particularly, but not exclusively, for the smallest stimulus luminance differences (Fig. 4).

Response accuracy increased from chance to maximal probability with increasing stimulus luminance difference, and the main effect of the low-dose ketamine injections was to shift the psychometric function to the left (Fig. 2D). This increase in response accuracy was thus reflected in a decrease in discrimination threshold, which in the example session changed from 8.8 to $6.0 \mathrm{~cd} / \mathrm{m}^{2}$ and corresponded to a shift in percentage contrast difference from 45.4 to $36.1 \%$. In each animal, we found a significant decrease in discrimination threshold following lowdose ketamine injections (Fig. 3B). As the dose increased, this decrease was diminished in monkey $\mathrm{G}$ and it was eliminated in monkey $\mathrm{F}$. In the latter animal, the highest ketamine dose tested $(0.75 \mathrm{mg} / \mathrm{kg})$ led to a significant decrease in discrimination threshold, i.e., a response-accuracy deterioration. In keeping with this rever-

Figure 2. Representative effects of ketamine on visual search performance (monkey $\mathrm{G}, 0.5 \mathrm{mg} / \mathrm{kg}$ ketamine). $\boldsymbol{A}$, Mean ( $\pm \mathrm{SE}$ ) saccade amplitude for $1 \mathrm{~min}$ intervals following the injection of ketamine. The gray shaded area indicates the epoch during which there was a significant decrease in saccade amplitude. The mean (including $\pm \mathrm{SE}$ ) saccade amplitude for the control block is indicated by the horizontal line. $\boldsymbol{B}$, Mean ( \pm SE) response latency for each minute following the injection of ketamine. $\boldsymbol{C}$, Mean ( \pm SE) response latency as a function of stimulus luminance difference before and after ketamine administration. $D$, Mean ( $\pm 95 \%$ $\mathrm{Cl}$ ) response accuracy as a function of stimulus luminance difference before and after ketamine administration. Ketamine increased the proportion of correct trials at intermediate stimulus luminance differences (see Materials and Methods) $\left(p<0.05, \chi^{2}\right.$ test), shifting the psychometric function to the left. Discrimination threshold was taken as the point at which the Weibull function reached $64 \%$ of its maximum (dashed line).

min, followed by a more gradual decay; response latency was still significantly increased at the end of this 40 min session. To capture the maximal effect of ketamine, our subsequent analyses considered only data from trials during this interval, which was also determined for the other two animals. In monkey F, saccade amplitude was also found to be consecutively significantly shorter from 2 to 19 min after ketamine injections, whereas it became nonsignificant after $17 \mathrm{~min}$ in monkey $\mathrm{H}$.

Response latency decreased with increasing stimulus luminance difference (Fig. 2C) and was significantly lengthened following ketamine injections across stimulus luminance differences ( $p<0.0001$, one-way ANOVA). Across animals, response latency increased in a dose-dependent manner and was significantly lengthened compared with the corresponding control latency (Fig. 3A). It is possible that this effect of ketamine on response latency is due to the slowing not only of perceptual processing but also of movement programming (Saito and Isa, 2003). To control for potential motor-related effects, we compared the response latency at each stimulus luminance difference in treatment blocks to that measured at the highest stimulus luminance difference $(86.1 \%$ contrast difference), to which we added the mean response latency measured in corresponding control trials to account for the observed decrease in latency with increasing stimulus luminance difference (Fig. 4, inset). With the duration of perceptual processing assumed to be minimal when contrast difference is maximal, most of the effect of ketamine on response latency can then be assigned to slowing in response programming. This is, however, not exactly the case because response latency in control blocks was in excess of $120 \mathrm{~ms}$, which is

sal, a single treatment with $1.0 \mathrm{mg} / \mathrm{kg}$ ketamine in monkey G led to no significant change in response accuracy and more than doubled response latency (data not shown). This dose of ketamine, however, seriously impaired the animal's behavior (see below), making it difficult to interpret the results of this single session on their own. Some of the differences between each animal's responses to treatment may be related to differences in ketamine sensitization between animals (see Materials and Methods).

The improvement in response accuracy following low-dose ketamine injections was associated with an increase in response latency, as would be expected from a speed-accuracy trade-off. Figure 5 illustrates this relationship for data obtained at the three intermediate levels of stimulus luminance difference and with the ketamine doses that yielded significantly lower discrimination thresholds ( $n=15$ ) (Fig. 3B, filled bars). A speed-accuracy tradeoff is also evidenced between the two animals that were comprehensively tested (monkey F and G) - the longer the animal's response latency in control blocks, the lower her discrimination threshold (Fig. 3). This was, however, generally not the case within a given control block, once trials were segregated into short and long response latency groups (i.e., median split). For instance, the percentage change in response accuracy [mean \pm 95\%; confidence interval (CI), $-1.6 \pm 7.8 \%$ ] for the 15 blocks considered above (Fig. 5) was not significantly different from zero ( $p=0.70, t$ test), even though the percentage change in response latency $(13.1 \pm 2.0 \%)$ was highly significant $(p<0.001$, $t$ test). It is possible that the response latency distribution within a block is not broad enough to translate into a difference in ac- 
curacy. In comparison, the change in response latency and accuracy between the control and treatment blocks in Figure 5 averaged $22.1 \pm 8.6 \%$ and $22.5 \pm 8.5 \%$, respectively. These observations suggest that a substantial increase in response latency is a prerequisite to observing improved accuracy. The low-dose ketamine injections in this study may have extended the latency distribution beyond what is normally observed.

To control for the effects of the vehicle, we also conducted experiments during which the animals received an injection of saline solution. We found negligible and inconsistent changes in response latency and discrimination threshold across all animals (Fig. 3). Similar results were obtained in the no-injection sessions, suggesting that waning motivation over time could not account for the effects of ketamine. As an additional measure of motivation, we calculated the rate at which the monkeys failed to fixate on the fixation spot and maintain fixation until the search display presentation (Table 1). For sessions in which ketamine was not injected, this rate was $\sim 3 \%$ of trials in the control block and $\sim 6 \%$ of trials in the subsequent treatment block, showing a small decrease in motivation. When the animals were injected with the lowest doses of ketamine $(0.25 \mathrm{mg} / \mathrm{kg})$, they broke fixation in comparable percentages of trials. Although larger in magnitude, the increase in these behavioral events with increasing ketamine doses remained moderate (on average, 9.7\% across all ketamine sessions). Only after the injection of $1.0 \mathrm{mg} / \mathrm{kg}$ ketamine in monkey $\mathrm{G}$ did we observe an excessively large increase in the rate of fixation break $(37.9 \%)$, indicating that this dose of ketamine seriously affected the animal's overall behavior. In summary, the main effects of ketamine on visual search performance, for injections $<1 \mathrm{mg} / \mathrm{kg}$, were unlikely to be due to the injection procedure or decreased motivation.

\section{Discussion}

We tested the hypothesis that the NMDA receptor plays a key role in the integration of neural activity during decision making by impairing their integrity using the NMDA antagonist ketamine while monkeys performed a visual search task. We found that low-dose ketamine injections led to an increase in response latency, which suggests that the process of neural activity integration underlying the accumulation of sensory evidence was slowed down. Contrary to the prediction that NMDA blockade would also cause the integration process to be noisier, search accuracy was found to improve. This differential effect of ketamine on visual search performance can, however, be explained with a competing accumulator model of neural activity integration, in which distinct populations of sensory-motor neurons integrate incoming sensory evidence about the choice alternatives and compete with one another through reciprocal inhibition until one population's activity grows sufficiently to trigger a response
Monkey G

Monkey F

Monkey $\mathrm{H}$
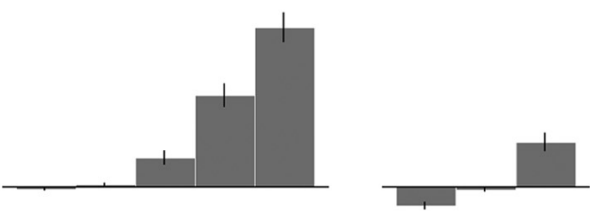

(no inj) (sal)
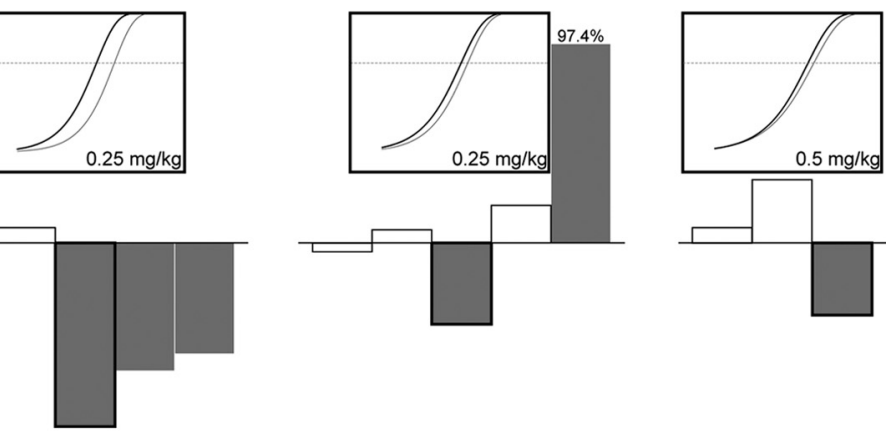

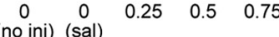

(no inj) $\stackrel{0}{(\text { sal })}$

0.5

Ketamine dose $(\mathrm{mg} / \mathrm{kg})$

(no inj) (sal)

Figure 3. Changes in response latency and discrimination threshold following ketamine and control treatments. $A$, Percentage $\pm 95 \% \mathrm{Cl}$ ) change in response latency for each animal and for each treatment, compared with corresponding control data (money $212 \pm 0.8 \mathrm{~ms}$; monkey $\mathrm{H}, 178 \pm 0.7 \mathrm{~ms}$ ). All percentage changes were significantly differen ( $p<0.05, t$ test). $\boldsymbol{B}$, Percentage change in discrimination threshold for each animal and for each treatment, compared with

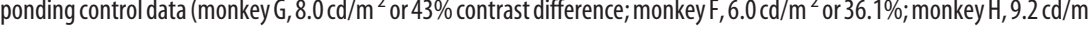
labels as in Fig. 2 D) for three example sessions (monkeys $\mathrm{G}$ and F, $0.25 \mathrm{mg} / \mathrm{kg}$; monkey H, $0.5 \mathrm{mg} / \mathrm{kg}$ ). Treatments with no injection (no inj) and saline injections (sal) are identified as treatments with $0 \mathrm{mg} / \mathrm{kg}$ ketamine dose.

(Usher and McClelland, 2001). Such a model not only explains how NMDA blockade produces an increase in response latency, because of the slowing down of the accumulation within each alternative neural representation, but also some improvement in response accuracy, because the reciprocal inhibition between neural representations can enhance any small difference over time.

The neural integration of sensory evidence has been proposed to rest on NMDA-mediated recurrent activation (Wang, 2002). Anatomically, this hypothesis is supported by the existence of Tglutaminergic recurrent collaterals throughout the cortex (Douglas and Martin, 2007), as well as in the SC (Moschovakis et al., 1988). These cortical recurrent collaterals are prevalent in layer III pyramidal neurons, which receive sensory inputs in sensory-motor areas like LIP and FEF, as well as in layer V pyramidal neurons within the same cortical areas, which project to the SC (Paré and Wurtz, 1997; Sommer and Wurtz, 2000). Our findings provide the first evidence that NMDA receptors are involved in the cellular mechanisms underlying the neural integration of sensory evidence, which has been observed in many neurons of the sensory-motor circuit involved in visual discrimination (Schall and Hanes, 1993; Thompson et al., 1996; Horwitz and Newsome, 1999; Kim and Shadlen, 1999; Shadlen and Newsome, 2001; McPeek and Keller, 2002; Shen and Paré, 2007; Thomas and Paré, 2007; Ogawa and Komatsu, 2009).

Competition between alternative neural representations could be subserved by local inhibitory networks combined with 


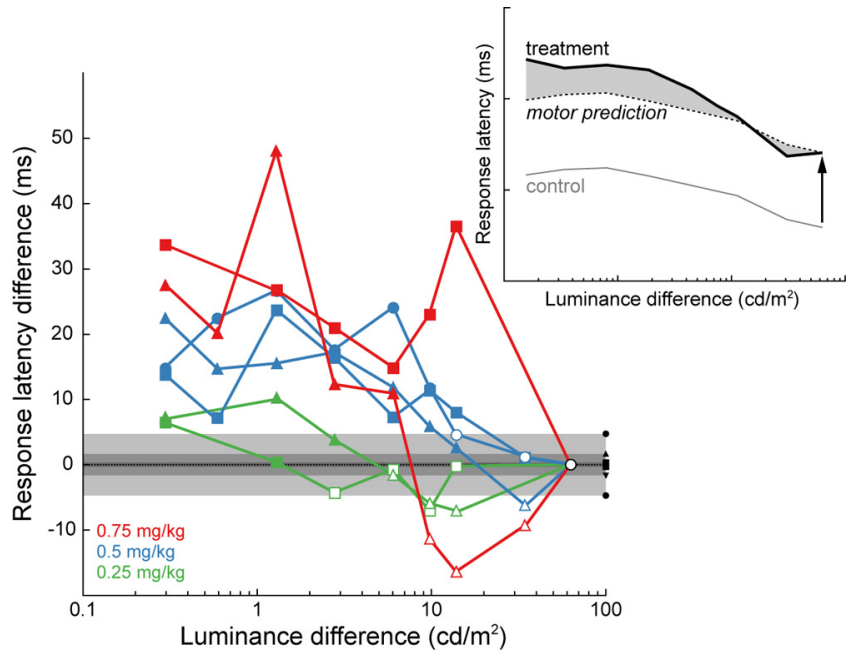

Figure 4. Difference between the response latency in treatment trials and that predicted by the sum of the mean response latency in the corresponding control session and at the highest contrast difference (86.1\%). Data from each animal is indicated by a different symbol (triangle, monkey G; square, monkey F; circle, monkey H). Response latency differences were determined to be statistically significant (solid symbols) if they exceeded by 2 SD the mean latency difference calculated in the saline sessions (black symbols and gray areas). Inset, Schematic of the calculation of response latency difference (shaded area): $\mathrm{RLD}_{\mathrm{x}}=\mathrm{TL}_{\mathrm{x}}-\left[\mathrm{CL}_{\mathrm{x}}+\left(\mathrm{TL}_{86.1 \%}-\right.\right.$ $\left.\left.\mathrm{CL}_{86.1 \%}\right)\right]$, where $R \mathrm{RD}_{x}$ is the response latency difference at $X$ luminance difference; $\mathrm{TL}_{\mathrm{x}}$ and $\mathrm{CL}_{\mathrm{x}}$ are the mean response latencies at $X$ luminance difference in the treatment and control blocks, respectively; and $\mathrm{TL}_{86.1 \%}$ and $\mathrm{CL}_{86.1 \%}$ are the mean treatment and control block latencies at the highest luminance difference. Inset example is from Figure $2 C$.

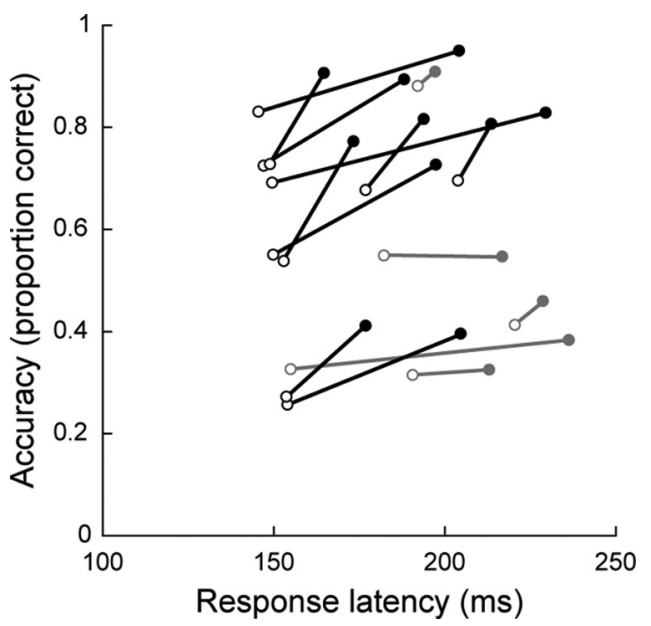

Figure 5. Response accuracy plotted as a function of mean response latency before $(\bigcirc)$ and after (-) treatment with ketamine. Data are from the trials with intermediate levels of stimulus luminance difference $(20.9,36.5$, and $48.0 \%$ contrast differences) for which the ketamine dose led to a significantly lower discrimination threshold (Fig. 3B). Black lines indicate significant increases in response accuracy ( $p<0.05, \chi^{2}$ tests). All data shown had significant increases in response latency ( $p<0.05$, rank sum tests). Average change in accuracy and latency was 0.11 (range, $0.004-0.24$ ) and $34.7 \mathrm{~ms}$ (range, $6-82$ ), respectively.

long-ranging horizontal connections, which have been identified both in cortex (Gilbert and Wiesel, 1979) and in SC (Behan and Kime, 1996). Such competition has been evidenced by the observations that distant neurons with nonoverlapping receptive fields show negatively correlated discharges both in cortex (Vaadia et al., 1995; Constantinidis et al., 2002; Cohen et al., 2010) and in SC (Day and Paré, 2005), consistent with the bias competition model of selective visual attention (Desimone and Duncan, 1995). The beneficial effect of ketamine on response accuracy diminished
Table 1. Average percentage (and $95 \% \mathrm{Cl}$ ) of trials in which fixation was either not initiated or maintained

\begin{tabular}{llc}
\hline Procedure & Control & Treatment \\
\hline No injection & $2.8(2.4-3.2)$ & $5.5(5.0-5.9)$ \\
Vehicle (saline) & $3.6(3.2-4.1)$ & $6.0(5.5-6.5)$ \\
Ketamine, $0.25 \mathrm{mg} / \mathrm{kg}$ & $3.2(2.6-3.7)$ & $5.3(4.3-6.3)$ \\
Ketamine, $0.5 \mathrm{mg} / \mathrm{kg}$ & $2.8(2.4-3.2)$ & $11.0(9.7-12.2)$ \\
Ketamine, $0.75 \mathrm{mg} / \mathrm{kg}$ & $3.0(2.5-3.6)$ & $13.1(11.4-14.8)$ \\
\hline
\end{tabular}

Data pooled across all three monkeys.

and disappeared with increasing doses, whereas response latency continued to worsen. This would be expected if ketamine blocked NMDA receptors in inhibitory interneurons (wide-arbor basket cells) more effectively than those in excitatory (pyramidal) neurons (Homayoun and Moghaddam, 2007; Seamans, 2008). Although pyramidal neurons in the rat's cortex have been shown to increase their discharge rate following NMDA antagonist treatments (Jackson et al., 2004), the late onset and modest magnitude of this increase suggest that this factor had a negligible impact on the rate of neural activity integration following the ketamine injections in our study. With larger ketamine doses, therefore, the neural representations of the alternatives become independent accumulators and response accuracy potentially worsens.

Injecting ketamine intramuscularly may have affected NMDA receptors in many neural circuits. For instance, we observed drifts in eye position following ketamine injection (Fig. $1 B$ ) consistent with dysfunction in the oculomotor system (Mettens et al., 1990). It is reasonable to argue that the observed increase in response latency could have been due to the impairment of early visual pathways, resulting in poor discrimination. Ketamine has been shown to impair the responsiveness of a broad range of neurons, including those in early visual pathways, such as in the lateral geniculate nucleus (Kwon et al., 1992) and primary visual cortex (Fox et al., 1990). Previous experiments have examined the effect of lesions in the magnocellular and parvocellular channels of the primate visual system (Schiller et al., 1990; Schiller, 1993). Unlike the processing of shape, color, texture, or movement, the processing of luminance difference remained intact following lesions in either channel at the level of the thalamus and extrastriate cortex. Since lesioning of the early visual pathways does not impair luminance discrimination, low doses of ketamine are unlikely to be detrimental to the animals' ability to discriminate the stimuli in our search display. The improved response accuracy observed at the lowest dose further argues against this unlikely possibility.

Ketamine has a limited affinity for the NMDA receptor and, at high doses, can interact with dopaminergic and serotonergic receptors (Javitt, 2004). We used very low doses of ketamine such that cross-interactions, if any, were likely minimal. To build upon these results, more specific antagonists such as dizocilpine (MK801), which has a tenfold affinity for the ion channel (Binns, 1999), could be used to ensure specificity. To examine more specific effects of NMDA receptor blockade on neural activity integration, such specific NMDA receptor antagonists would have to be injected into FEF, LIP, and SC while monkeys perform visual discrimination tasks and neuronal activity is recorded.

A large body of work has shown that the NMDA receptor plays a role in the maintenance of working memory (Krystal et al., 1994; Lisman et al., 1998) and multisensory integration (Binns and Salt, 1996) as well as in long-term synaptic plasticity that may substantiate long-term memory (Collingridge et al., 1983; Kerchner and Nicoll, 2008). This study provides evidence that NMDA re- 
ceptors are also involved in the neural activity integration underlying the decision-making process involved in visual search and perhaps other discrimination tasks. Blocking NMDA in this pathway is presumed to lengthen the integration time of this process and to benefit discrimination due to competition between the neural representations of the choice alternatives.

\section{References}

Behan M, Kime NM (1996) Intrinsic circuitry in the deep layers of the cat superior colliculus. Vis Neurosci 13:1031-1042.

Bergen JR, Julesz B (1983) Parallel versus serial processing in rapid pattern discrimination. Nature 303:696-698.

Bichot NP, Schall JD (1999) Effects of similarity and history on neural mechanisms of visual selection. Nat Neurosci 2:549-554.

Binns KE (1999) The synaptic pharmacology underlying sensory processing in the superior colliculus. Prog Neurobiol 59:129-159.

Binns KE, Salt TE (1996) Importance of NMDA receptors for multimodal integration in the deep layers of the cat superior colliculus. J Neurophysiol 75:920-930.

Bodelón C, Fallah M, Reynolds JH (2007) Temporal resolution for the perception of features and conjunctions. J Neurosci 27:725-730.

Bogacz R (2007) Optimal decision-making theories: linking neurobiology with behaviour. Trends Cogn Sci 11:118-125.

Britten KH, Shadlen MN, Newsome WT, Movshon JA (1992) The analysis of visual motion: a comparison of neuronal and psychophysical performance. J Neurosci 12:4745-4765.

Brunamonti E, Clarence WM, Ferraina S, Paré M (2007) Effects of ketamine on saccade countermanding performance in macaque monkeys. Soc Neurosci Abstr 33:719.5.

Clarence WM, Scott JP, Dorris MC, Paré M (2006) Use of enclosures providing vertical dimension by captive rhesus monkeys (Macaca mulatta) involved in biomedical research. J Am Assoc Lab Anim Sci 45:31-34.

Cohen JY, Crowder EA, Heitz RP, Subraveti CR, Thompson KG, Woodman GF, Schall JD (2010) Cooperation and competition among frontal eye field neurons during visual target selection. J Neurosci 30:3227-3238.

Collingridge GL, Kehl SJ, McLennan H (1983) Excitatory amino acids in synaptic transmission in the Schaffer collateral-commissural pathway of the rat hippocampus. J Physiol 334:33-46.

Condy C, Wattiez N, Rivaud-Péchoux S, Gaymard B (2005) Ketamineinduced distractibility: An oculomotor study in monkeys. Biol Psychiatry 57:366-372.

Constantinidis C, Williams GV, Goldman-Rakic PS (2002) A role for inhibition in shaping the temporal flow of information in prefrontal cortex. Nat Neurosci 5:175-180.

Day GS, Paré M (2005) Saccade target selection by coordination and competition in superior colliculus neuronal ensembles. Soc Neurosci Abstr 31:475.6.

Desimone R, Duncan J (1995) Neural mechanisms of selective visual attention. Annu Rev Neurosci 18:193-222.

Douglas RJ, Martin KA (2007) Recurrent neuronal circuits in the neocortex. Curr Biol 17:R496-R500.

Durstewitz D, Seamans JK (2006) Beyond bistability: biophysics and temporal dynamics of working memory. Neuroscience 139:119-133.

Fox K, Sato H, Daw N (1990) The effect of varying stimulus intensity on NMDA-receptor activity in cat visual cortex. J Neurophysiol 64:1413-1428.

Gilbert CD, Wiesel TN (1979) Morphology and intracortical projections of functionally characterised neurones in the cat visual cortex. Nature 280:120-125.

Homayoun H, Moghaddam B (2007) NMDA receptor hypofunction produces opposite effects on prefrontal cortex interneurons and pyramidal neurons. J Neurosci 27:11496-11500.

Horwitz GD, Newsome WT (1999) Separate signals for target selection and movement specification in the superior colliculus. Science 284:1158-1161.

Jackson ME, Homayoun H, Moghaddam B (2004) NMDA receptor hypofunction produces concomitant firing rate potentiation and burst activity reduction in the prefrontal cortex. Proc Natl Acad Sci USA 101:8467-8472.

Javitt DC (2004) Glutamate as a therapeutic target in psychiatric disorders. Mol Psychiatry 9:984-997.
Kalwarowsky S, Clarence WM, Shen K, Paré M (2008) Low doses of ketamine lengthen response time and improve response accuracy during visual search. Soc Neurosci Abstr 34:165.1.

Kerchner GA, Nicoll RA (2008) Silent synapses and the emergence of a postsynaptic mechanism for LTP. Nat Rev Neurosci 9:813-825.

Kiani R, Hanks TD, Shadlen MN (2008) Bounded integration in parietal cortex underlies decisions even when viewing duration is dictated by the environment. J Neurosci 28:3017-3029.

Kim JN, Shadlen MN (1999) Neural correlates of a decision in the dorsolateral prefrontal cortex of the macaque. Nat Neurosci 2:176-185.

Krystal JH, Karper LP, Seibyl JP, Freeman GK, Delaney R, Bremner JD, Heninger GR, Bowers MB Jr, Charney DS (1994) Subanesthetic effects of the noncompetitive NMDA antagonist, ketamine, in humans: psychotomimetic, perceptual, cognitive, and neuroendocrine responses. Arch Gen Psychiatry 51:199-214.

Kwon YH, Nelson SB, Toth LJ, Sur M (1992) Effect of stimulus contrast and size on NMDA receptor activity in cat lateral geniculate nucleus. J Neurophysiol 68:182-196.

Lisman JE, Fellous JM, Wang XJ (1998) A role for NMDA-receptor channels in working memory. Nat Neurosci 1:273-275.

McPeek RM, Keller EL (2002) Saccade target selection in the superior colliculus during a visual search task. J Neurophysiol 88:2019-2034.

Mettens P, Godaux E, Cheron G (1990) Effects of ketamine on ocular movements of the cat. J Vestib Res 1:325-338.

Mongillo G, Barak O, Tsodyks M (2008) Synaptic theory of working memory. Science 319:1543-1546.

Moschovakis AK, Karabelas AB, Highstein SM (1988) Structure-function relationships in the primate superior colliculus. I. Morphological classification of efferent neurons. J Neurophysiol 60:232-262.

Ogawa T, Komatsu H (2009) Condition-dependent and conditionindependent target selection in the macaque posterior parietal cortex. J Neurophysiol 101:721-736.

Paré M, Munoz DP (1996) Saccadic reaction time in the monkey: advanced preparation of oculomotor programs is primarily responsible for express saccades occurrence. J Neurophysiol 76:3666-3681.

Paré M, Wurtz RH (1997) Monkey posterior parietal cortex neurons antidromically activated from superior colliculus. J Neurophysiol 78:3493-3497.

Ratcliff R, Rouder JN (2000) A diffusion model account of masking in twochoice letter identification. J Exp Psychol Hum Percept Perform 26:127-140.

Roitman JD, Shadlen MN (2002) Response of neurons in the lateral intraparietal area during a combined visual discrimination reaction time task. J Neurosci 22:9475-9489.

Saarinen J (1988) The effect of exposure duration on the analysis of spatial structure in eccentric vision. Spat Vis 3:1-7.

Saito Y, Isa T (2003) Local excitatory network and NMDA receptor activation generate a synchronous and bursting command from the superior colliculus. J Neurosci 23:5854-5864.

Schall JD, Hanes DP (1993) Neural basis of saccade target selection in frontal eye field during visual search. Nature 366:467-469.

Schiller PH (1993) The effects of V4 and middle temporal (MT) area lesions on visual performance in the rhesus monkey. Vis Neurosci 10:717-746.

Schiller PH, Logothetis NK, Charles EK (1990) Functions of the colouropponent and broad-band channels of the visual system. Nature 343:68-70.

Seamans J (2008) Losing inhibition with ketamine. Nat Chem Biol 4:91-93. Shadlen MN, Newsome WT (2001) Neural basis of a perceptual decision in the parietal cortex (area LIP) of the rhesus monkey. J Neurophysiol 86:1916-1936.

Shen K, Paré M (2006) Guidance of eye movements during visual conjunction search: local and global contextual effects on target discriminability. J Neurophysiol 95:2845-2855.

Shen K, Paré M (2007) Neuronal activity in superior colliculus signals both stimulus identity and saccade goals during visual conjunction search. J Vis 7:15.1-15.13.

Shibuya H, Bundesen C (1988) Visual selection from multielement displays: measuring and modeling effects of exposure duration. J Exp Psychol Hum Percept Perform 14:591-600.

Shiigi Y, Casey DE (1999) Behavioral effects of ketamine, an NMDA gluta- 
matergic antagonist, in non-human primates. Psychopharmacology (Berl) 146:67-72.

Smith PL, Ratcliff R (2004) Psychology and neurobiology of simple decisions. Trends Neurosci 27:161-168.

Sommer MA, Wurtz RH (2000) Composition and topographic organization of signals sent from the frontal eye field to the superior colliculus. J Neurophysiol 83:1979-2001.

Stoet G, Snyder LH (2006) Effects of the NMDA antagonist ketamine on task-switching performance: evidence for specific impairments of executive control. Neuropsychopharmacology 1:1675-1681.

Thomas NW, Paré M (2007) Temporal processing of saccade targets in parietal cortex area LIP during visual search. J Neurophysiol 97:942-947.

Thompson KG, Hanes DP, Bichot NP, Schall JD (1996) Perceptual and mo- tor processing stages identified in the activity of macaque frontal eye field neurons during visual search. J Neurophysiol 76:4040-4055.

Usher M, McClelland JL (2001) The time course of perceptual choice: the leaky, competing accumulator model. Psychol Rev 108:550-592.

Vaadia E, Haalman I, Abeles M, Bergman H, Prut Y, Slovin H, Aertsen A (1995) Dynamics of neuronal interactions in monkey cortex in relation to behavioural events. Nature 373:515-518.

Verghese P, Nakayama K (1994) Stimulus discriminability in visual search. Vision Res 34:2453-2467.

Wang XJ (2002) Probabilistic decision making by slow reverberation in cortical circuits. Neuron 36:955-968.

Weibull W (1951) A statistical distribution function of wide applicability. J Appl Mech 18:293-297. 